\title{
Photosynthetic Responses of Seedlings of two Indigenous Plants inside Exotic Tree Plantations and adjacent Natural Forest in Munessa-Shashemene Forest, SouthernEthiopia
}

\section{Desalegn Tadele ${ }^{1 *}$ and Masresha Fetene ${ }^{2}$}

${ }^{1}$ Department of Biology,College of Science, BahirDar University, P.O. Box1817, Bahir Dar, Ethiopia. (*desalegn64@yahoo.com)

${ }^{2}$ Department of Biology, College of Science, P.O. Box 1176, Addis Ababa University, Addis Ababa, Ethiopia.

\begin{abstract}
The potential role of exotic tree plantations in facilitating successional processes on degraded areas was evaluated in southern Ethiopia, Munessa-Shashemene forest, by examining photosynthetic responses of Bersamaabyssinica Fres. and Croton macrostachyusDel. seedlings naturally grown inside plantations of Eucalyptussaligna and Pinuspatula and adjacent natural forest. Photosynthetic responses of the seedlings were recorded using modulated photosynthesis yield analyzer, Mini-PAM. Analysis of fluorescence parameters in the leaves showed no significant differences in the level of dark-adapted and light-adapted fluorescence yield $\left(\mathrm{F}_{\mathrm{v}} / \mathrm{F}_{\mathrm{m}}\right.$ and $\Delta \mathrm{F} / \mathrm{F}_{\mathrm{m}}$, respectively) among seedlings grown inside plantations and adjacent natural forest indicating similar photosynthetic performance. The light response curves of electron transport rate $(E T R)$, light-adapted fluorescence yield $\left(\Delta F / F_{m}\right)$ and non-photochemical quenching (NPQ)showed similar light saturation behavior among the seedlings grown inside plantations and natural forest and suggested a shade-adapted behavior of Bersamaabyssinica as compared to Croton macrostachyus. The results suggest the role of exotic tree plantationsin facilitating restoration processes on degraded areas by improving light conditions for photosynthesis.
\end{abstract}

Keywords: Chlorophyll fluorescence, Light response curves, PS II, Restoration, Ethiopia.

\section{INTRODUCTION}

Recent approaches for the development of suitable strategies for forest regeneration focus on use of plantation systems, especially with fast growing plantation species, that serve to restore degraded areas. Several studies conducted so far in Ethiopia and elsewhere have shown enhanced regeneration, establishment and succession of native plants inside plantations of exotic tree species (Lugo, 1997; Parrotta et al., 1997; Feyera Senbeta and Demel Teketay, 2001; Feyera Senbeta et al., 2002; Senbeta Feyera et al., 2002; Bekele Lemma et al., 2006; Getachew Tesfayeand Abiyot Berhanu, 2006; Guerrero and Bustamante, 2007; Shiferaw Alem and Tadesse Woldemariam, 2009; Shiferaw Alem et al., 2010). The role of forest plantations in promoting restoration processes on degraded areas can be influenced by several factors including site conditions, land use history, age of plantations and availability of seed source (Feyera Senbeta 
and Demel Teketay, 2001; Feyera Senbeta et al., 2002; Senbeta Feyera et al., 2002; Mulugeta Lemenih and Demel Teketay, 2005).Plantation species themselves also possess different qualities in facilitating natural regeneration of native plants under their canopies. Mulugeta Lemenih et al. (2004) and Eshetu Yirdawand Luukkanen (2004), for example, reported variations in understory light environment of forest plantations which would cause differences among over story plantation species in promoting natural regeneration of native species.

Though light is the most important factor that determines growth and survival of understory plants in forest plantations (Ostertag et al., 2008), and has very considerable role for the selection of suitable native species under different plantations (Wang et al., 2009), the focus of most previous studies conducted in Ethiopia was mainly on the diversity and density of natural regeneration of woody species inside plantation forests. To facilitate succession inside plantation forests to more native forests, information on growth and eco-physiology of native species is required to relate plantation conditions, especially understory light regime (EshetuYirdawandLuukkanen,2004), with seedling characteristics (Wang et al., 2009). The rationale for this study is thus to provide eco-physiological information of tropical forest species to facilitate restoration activities through tree plantations. In this study we examined the photosynthesis of seedlings of two indigenous plants, Bersamaabyssinica Fres. and Croton macrostachyus Del., naturally established inside plantations of Eucalyptus saligna and Pinuspatula and in an adjacent natural montane forest. Bersamaabyssinica Fres. and Croton macrostachyus Del. (hereafter referred to as Bersama and Croton, respectively) are found to grow naturally under tree plantations (Desalegn Tadele, 2004; Mulugeta Lemenih et al., 2004; Mulugeta Lemenih and Demel Teketay, 2005). The paper is aimed to answer the following questions: Do seedlings of the study species differ in photosynthetic responses among plantations and natural forest? Do plantation forests create light environment conducive for growth of indigenous seedlings?

\section{METHODOLOGY}

\subsection{Study Area}

The study was conducted in Degaga District of Munessa-Shashemene forest at the eastern escarpment of the Great Rift Valley, southern Ethiopia (Fig 1). This forest is one of the 58 Priority Forest Areas of Ethiopia with a total area of 98,169 ha out of which 17,223 ha is remnant 
natural forest and 6,791 ha is exotic tree plantations. It is a dry Afromontane forest located about $250 \mathrm{~km}$ south of Addis Ababa at $7^{\circ} 13^{\prime} \mathrm{N}$ and $38^{\circ} 37^{\prime} \mathrm{E}$ and covers an altitudinal range between 2100 and $2700 \mathrm{~m}$. Soils of the study area are classified as Mollic Nitisols (Fritzsche et al., 2006). The main rainy season extends from mid-June to mid-October with maximum rainfall occurring between July and August. The mean annual rainfall is about 1,250 mm, and the mean annual temperature ranges between $15-20^{\circ} \mathrm{C}$.

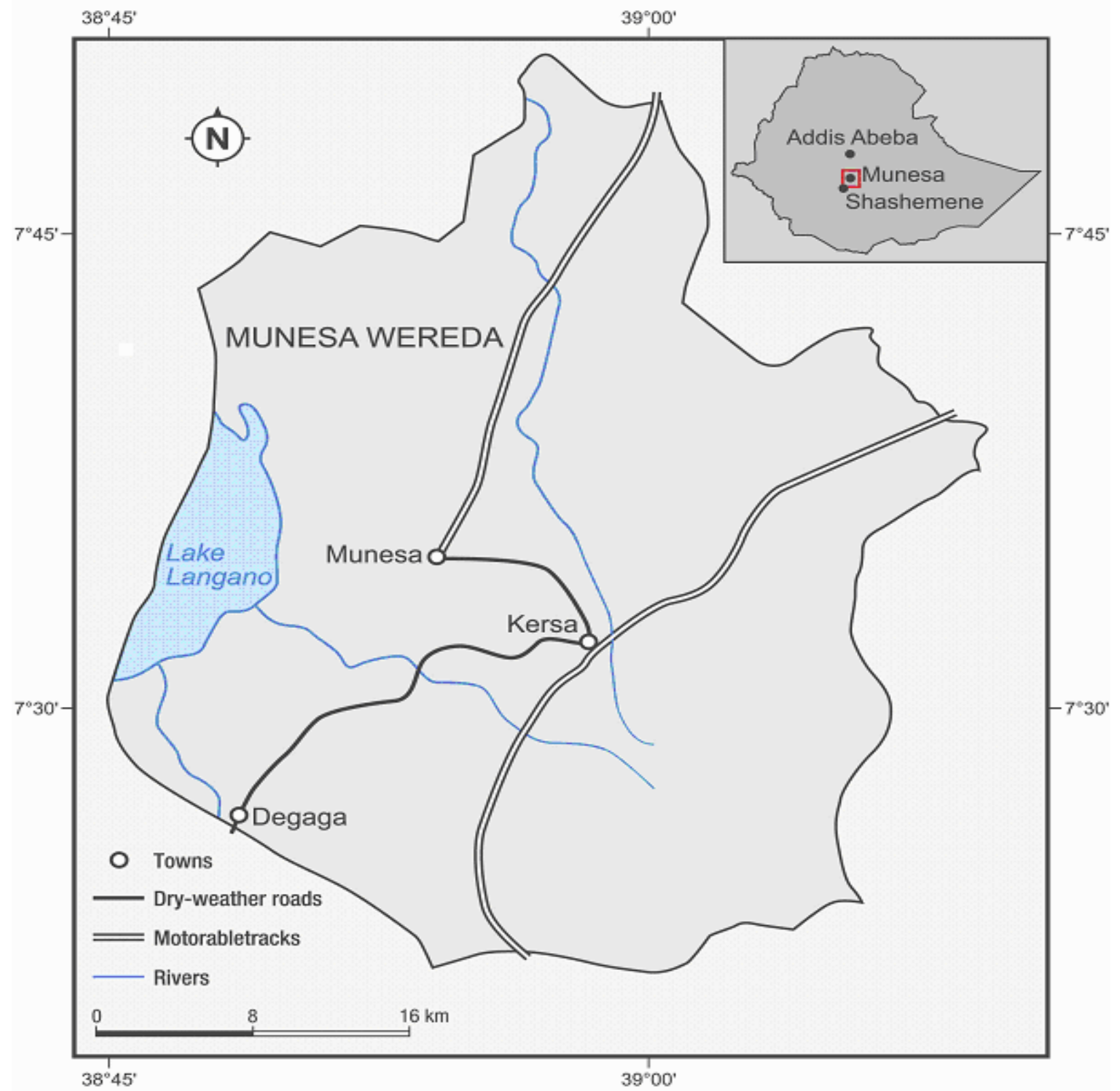

Figure 1. Map of the study area. 


\subsection{Plantation Stands Sampling}

Cupressuslusitanica, Eucalyptus spp. and Pinuspatula are the major exotic plantation species at Munessa-Shashemen Forest. For this study, two exotic plantation species, Eucalyptussaligna and Pinuspatula and adjacent montane natural forest were chosen. The plantations were $0.5 \mathrm{~km}$ apart from each other and close to the natural forest. These plantation species were chosen primarily for high natural regeneration of indigenous species under their canopies (Desalegn Tadele, 2004). And secondly they were very close to the natural forest so that evaluation of their effect on photosynthesis of indigenous seedlings was possible. Characteristics of sampled sites are given in table 1 .

Table 1. Sampled site characteristics (age, leaf area index (LAI), number of individuals ha ${ }^{-1}$ (density), diameter at breast height (DBH) and silviculture) of study plots at MunessaShashemene forest.

\begin{tabular}{|llllll|}
\hline Sampled site & Age (years) & LAI & Density & DBH $(\mathrm{cm})$ & Silvicultural treatments \\
\hline E. saligna & 17 & 1.72 & 1012 & 31 & $1^{\text {st }}$ rotation thinned \\
\hline P. patula & 31 & 2.40 & 823 & 33.5 & $1^{\text {st }}$ rotation thinned \\
\hline Natural forest & - & 1.80 & $951^{*}$ & $25^{*}$ & $\begin{array}{l}\text { Disturbance (grazing and } \\
\text { selective cutting) }\end{array}$ \\
\hline
\end{tabular}

*Measurement was made for individuals with $\mathrm{DBH} \geq 10 \mathrm{~cm}$.

\subsection{Chlorophyll Fluorescence of PS II}

Chlorophyll fluorescence was recorded in situ with a portable pulse-amplitude modulated photosynthesis yield analyzer (Mini-PAM, Heinz Walz, Effeltrich, Germany) equipped with a standard 2030-B leaf clip holder. Four seedlings per species per site were selected to monitor florescence parameters. Data were collected on three leaves taken at random from each seedling in the morning (07:00-09:00), midday (11:30-13:30) and afternoon (15:30-17:30). Potential quantum yield of PS II $\left.\left(\mathrm{F}_{\mathrm{m}}-\mathrm{F}_{\mathrm{o}}\right) / \mathrm{F}_{\mathrm{m}}=\mathrm{F}_{\mathrm{v}} / \mathrm{F}_{\mathrm{m}}\right)$ was measured following Lüttge et al.(2001) in the early morning and during the day after darkening the leaves for $30 \mathrm{~min}$, where $\mathrm{F}_{\mathrm{o}}$ is the minimal fluorescence level of dark-adapted leaves with all PS II reaction centers open, $\mathrm{F}_{\mathrm{m}}$ is the maximal fluorescence level with all PS II reaction centers closed, determined by a saturating light pulse at $3000 \mu \mathrm{mol} \mathrm{m} \mathrm{m}^{-2}$ on dark-adapted leaves, and $\mathrm{F}_{\mathrm{v}}$ is the maximal variable fluorescence level. Effective quantum yield of PS II was calculated as $\left(F_{m}-F\right) / F_{m}{ }^{\prime}=\Delta F / F_{m}$ (Genty et al., 1989), 
where $\mathrm{F}$ is the steady-state value of fluorescence of light-adapted leaf and $\mathrm{F}_{\mathrm{m}}$ ' is the maximal fluorescence level in the light-adapted state determined by saturating light pulse at $3000 \mu \mathrm{molm}^{-2}$ $\mathrm{s}^{-1}$ superimposed on the prevailing environmental light flux. Non-photochemical quenching (NPQ) was calculated by Stern-Volmer equation as NPQ $=\left(\mathrm{F}_{\mathrm{m}} / \mathrm{F}_{\mathrm{m}}{ }^{\prime}\right)-1$ (Bilger et al., 1995). Apparent rate of photosynthetic electron transport (ETR) was determined as $\Delta \mathrm{F} / \mathrm{F}_{\mathrm{m}} \times \mathrm{PAR} \times 0.5$ x 0.84, where the factor 0.5 accounts for the excitation of PS II and the factor 0.84 assumes a reflection of $16 \%$ PAR (photosynthetically active radiation) at the leaf surface (Schreiber et al., 1994).

Light response curves of $\Delta \mathrm{F} / \mathrm{F}_{\mathrm{m}}$, ETR and NPQ were constructed using the light curve programme of the photosynthesis yield analyzer. Leaves were irradiated with a series of progressively increased actinic light intensities without prior dark acclimation. The light was provided by the instrument's internal light source. Measurements were obtained over a range of PAR values which increased in eight steps within $4 \mathrm{~min}$ at $30 \mathrm{~s}$ interval. The measurements were taken on three leaves from four seedlings of each species in each stand.

\subsection{Data Analysis}

All statistical analyses were done using SPSS Version 16. Prior to analysis, data were tested for normality using Chi-square goodness of fit. Differences among means at the various sites were assessed by ANOVA according to general linear model (GLM) procedure. Significant differences at the different sites were found through Tukey's Honestly Significant Difference Test. Deviation of potential quantum yield of photosystem II of 30 min dark-adapted leaves from the optimum value, 0.8 (Demmig and Björkman, 1987) was identified using Student's $t$-test at $P$ $=0.05$. To all citations of significant differences in the text, differences between means were considered significant when $p<0.05$.

\section{RESULTS}

\subsection{Diurnal values of $F_{v} / F_{m}$ and $\Delta F / F_{m}$,}

Chlorophyll fluorescence in the leaves of Bersama and Croton seedlings was measured to evaluate photosynthetic performance in different environments. There was no much difference in chlorophyll fluorescence parameters among leaves of Bersama and Croton seedlings grown inside plantations and natural forest. The value of potential quantum yield of PS II, $F_{v} / F_{m}$, remained almost constant throughout the day and no significant difference was found in leaves of 
the study species grown in both plantation and natural forest (Table 2). Furthermore, except for some measurements during the midday, the values of $\mathrm{F}_{\mathrm{v}} / \mathrm{F}_{\mathrm{m}}$ were not significantly different from 0.8, which could indicate optimal quantum efficiency of unstressed leaves (Demmig and Björkman, 1987). Effective quantum yield of PS II, $\Delta \mathrm{F} / \mathrm{F}_{\mathrm{m}}$, was uniform but tended to decline around the midday (Table3). Here the studyplants also showed no significant differences across the study sites.

Table 2.Potential quantum yield of PS II, $\mathrm{F}_{\mathrm{v}} / \mathrm{F}_{\mathrm{m}}$, of 30 min dark-adapted leaves in the morning, midday and afternoon of the study species at the different sites.

\begin{tabular}{|lllll|}
\hline Species & Sites & Morning & Midday & Afternoon \\
\hline Croton & Natural forest & $0.79 \pm 0.07 \mathrm{a}$ & $0.79 \pm 0.01 \mathrm{ab}$ & $0.79 \pm 0.05 \mathrm{ab}$ \\
& Eucalyptus plantation & $0.81 \pm 0.02 \mathrm{~b}$ & $0.80 \pm 0.01 \mathrm{~b}$ & $0.81 \pm 0.08 \mathrm{~b}$ \\
& Pinus Plantation & $0.80 \pm 0.02 \mathrm{ab}$ & $0.79 \pm 0.03 \mathrm{a}^{*}$ & $0.81 \pm 0.04 \mathrm{~b}$ \\
Bersama & Natural forest & $0.79 \pm 0.06 \mathrm{a}$ & $0.77 \pm 0.06 \mathrm{c}^{*}$ & $0.79 \pm 0.05 \mathrm{ab}$ \\
& Eucalyptus plantation & $0.80 \pm 0.03 \mathrm{ab}$ & $0.78 \pm 0.03 \mathrm{ac}$ & $0.79 \pm 0.04 \mathrm{a}^{*}$ \\
& Pinus Plantation & $0.79 \pm 0.02 \mathrm{ab}$ & $0.77 \pm 0.04 \mathrm{c}^{*}$ & $0.80 \pm 0.01 \mathrm{ab}$ \\
\hline
\end{tabular}

Values are means \pm S.D. $(n=12)$. Means in a column or row with the same letter are not different significantly at $p<0.05$. *Indicates values significantly smaller than 0.8 at $p<0.05$ using Student's $t$-test.

Table 3. Effective quantum yield of PS II, $\Delta \mathrm{F} / \mathrm{F}_{\mathrm{m}}$, of light-adapted leaves in the morning, midday and afternoon of the study species at the different sites.

\begin{tabular}{|lllll|}
\hline Species & Sites & Morning & Midday & Afternoon \\
\hline Croton & Natural forest & $0.79 \pm 0.02 \mathrm{a}$ & $0.74 \pm 0.05 \mathrm{a}$ & $0.79 \pm 0.07 \mathrm{a}$ \\
& Eucalyptus plantation & $0.79 \pm 0.02 \mathrm{a}$ & $0.72 \pm 0.01 \mathrm{a}$ & $0.78 \pm 0.05 \mathrm{a}$ \\
& Pinus Plantation & $0.77 \pm 0.06 \mathrm{ab}$ & $0.68 \pm 0.03 \mathrm{~b}$ & $0.77 \pm 0.06 \mathrm{a}$ \\
Bersama & Natural forest & $0.74 \pm 0.04 \mathrm{bc}$ & $0.73 \pm 0.02 \mathrm{a}$ & $0.76 \pm 0.06 \mathrm{bc}$ \\
& Eucalyptus plantation & $0.76 \pm 0.03 \mathrm{bc}$ & $0.70 \pm 0.03 \mathrm{~b}$ & $0.77 \pm 0.01 \mathrm{ab}$ \\
& Pinus Plantation & $0.74 \pm 0.01 \mathrm{c}$ & $0.72 \pm 0.05 \mathrm{a}$ & $0.75 \pm 0.01 \mathrm{c}$ \\
\hline
\end{tabular}

Values are means \pm S.D. $(n=12)$. Means in a column or row with the same letter are not different significantly at $p<0.05$.

\subsection{Light Response Curves}

Light response curves of non-photochemical quenching (NPQ), electron transport rate (ETR) and effective quantum yield( $\Delta \mathrm{F} / \mathrm{Fm}$ ') of Bersama and Croton seedlings grown inside plantations and adjacent natural forest are presented in figure $2(\mathrm{~A} \& \mathrm{~B})$. With the increase of actinic light, $\Delta \mathrm{F} / \mathrm{F}_{\mathrm{m}}$, 
significantly declined while NPQ and ETR increased with ETR being leveled off at high light (750-1040 $\left.\mu \mathrm{mol} \mathrm{m} \mathrm{m}^{-2}\right)$.Croton had maximum ETR at $1040 \mu \mathrm{mol} \mathrm{m} \mathrm{s}^{-2}$ and Bersamaat750 $\mu \mathrm{mol}$ $\mathrm{m}^{-2} \mathrm{~s}^{-1}$. Maximum values of ETR were also greater in seedlings of Croton at all the study sites. Bersama had steeper light response curves in the natural forest in the early phases of the response curves. Whereas, Croton had its steeper response curves in the early phase in Pinus plantation. Overall, differences in photosynthetic responses among individuals of each species across the study sites were marginal as compared to differences among individuals of the two species at the same site.

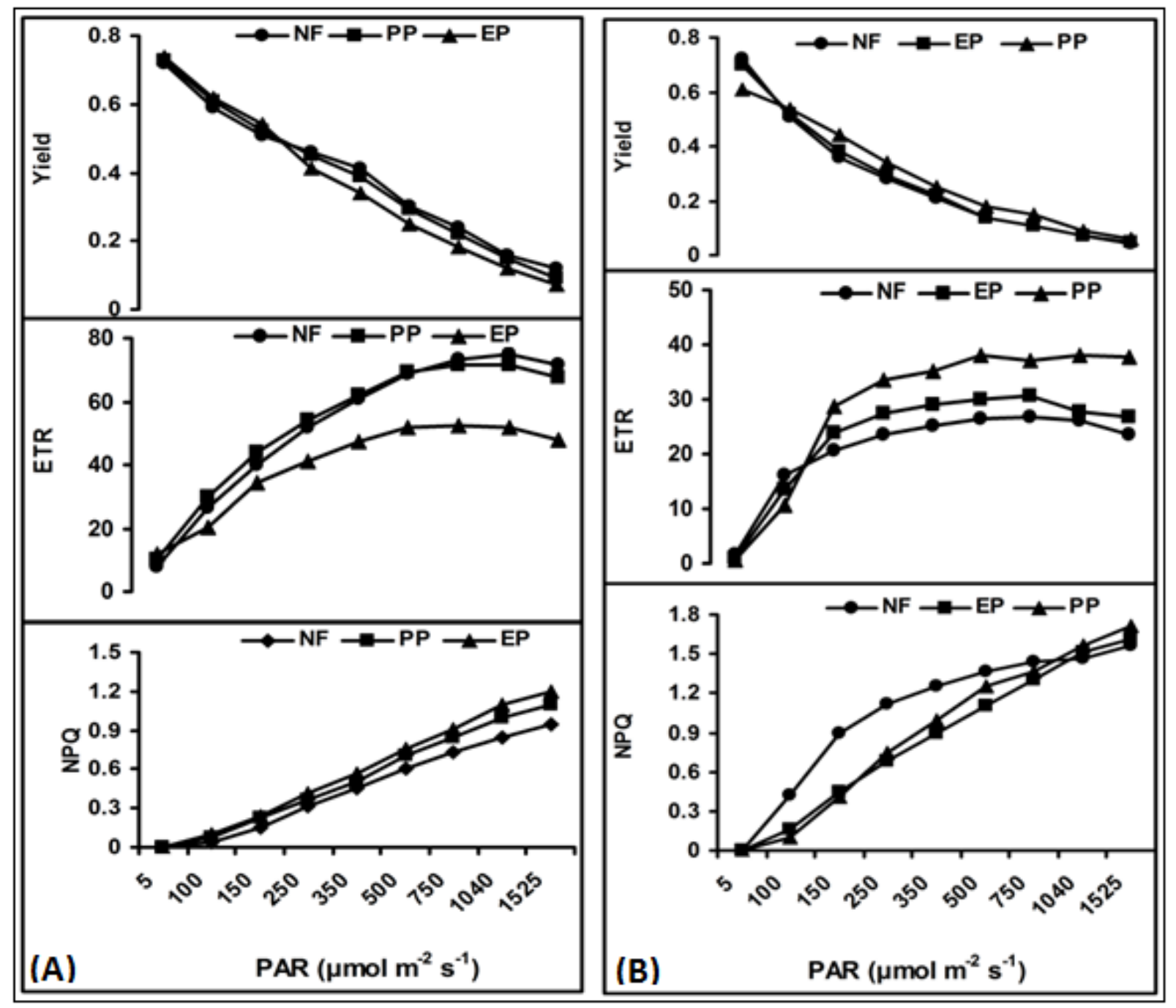

Figure 2.Light response curves of chlorophyll fluorescence parameters in seedlings ofCroton (A) and Bersama (B) grown inside natural forest (NF), Eucalyptus plantation (EP) and Pinus plantation (PP). 


\section{DISCUSSION}

In the present study, we assessed photosynthetic responses of Bersama and Croton seedlings grown inside forest plantations and natural forest by determining fluorescence parameters. The values of fluorescence parameters, $\mathrm{F}_{\mathrm{v}} / \mathrm{F}_{\mathrm{m}}$ and $\Delta \mathrm{F} / \mathrm{F}_{\mathrm{m}}$, in the leaves of Bersama and Croton seedlings showed that photosynthetic responses of the seedlings were not different between forest plantation and natural forest. $\mathrm{F}_{\mathrm{v}} / \mathrm{F}_{\mathrm{m}}$ was around the optimum value, 0.8 , suggesting normal unstressed leaves prior to measurement and good photosynthetic performance (Björkman, 1987; Demmig and Björkman, 1987). However, $F_{v} / F_{m}$ declined at midday indicating reduced photosynthesis. Interestingly, the reduction at the midday was not significant between plantations and natural forest and become reversed in the afternoon which shows the absence of photodamage to PS II.

To assess the potential photosynthetic performance of study species at different sites, light response curves of ETR, $\Delta \mathrm{F} / \mathrm{F}_{\mathrm{m}}$, and NPQ were obtained. The curves suggested similar light saturation behavior of Croton and Bersama seedlings inside plantations and natural forest reflecting that the seedlings were experiencing similar light environment. Though not statistically significant, the seedlings of Bersama tended to develop a sequence of light-adapted to shadeadapted behavior in Eucalyptus plantation >Pinus plantation> Natural forest. Croton had a sequence of the above behavior in Natural forest $>$ Eucalyptus plantation $>$ Pinus plantation. It needs to be noted however that the natural forest where measurements from Croton were taken was more open compared to that of Bersama due to its high light demanding nature (Gemedo Dalle and Masresha Fetene, 2004). Almost in all sites, values of $\Delta \mathrm{F} / \mathrm{F}_{\mathrm{m}}$ ' and ETR were low in Bersama and high in Croton. The light response curve suggested shade-adapted behavior of Bersama as compared to Croton. Gemedo Dalle and Masresha Fetene (2004) classified Bersama as shade tolerant species and Croton as light demander species.

The absence of disparity in photosynthesis yield of indigenous species in the study sites showed that plantation forests may facilitate growth of established seedlings by stimulating light conditions, an important factor that determines growth and survival of understory plants in forest plantations (Ostertag et al., 2008), closely similar to the growing conditions in the natural forests. The canopies of plantation species determine growth of colonizing species by affecting the light environment received at the forest floor. Plantation forests can catalyze restoration processes on deforested areas by providing protection for the growth of colonizing understory vegetation from 
high light stress (Desalegn Tadele and Masresha Fetene, 2013).Light condition at the forest floor of tree plantationsin southern Ethiopia was found to cause significant influence on species richness and growth of colonized woody species (Mulugeta Lemenih et al., 2004).Specifically, Yang et al. (2009) reported two exotic Acacia species to act as nurse plants for understory plants by improving light conditions for photosynthesis.

\section{CONCLUSION}

Seedlings of the study species photosynthetically performed well inside Eucalyptus and Pinus plantations reflecting that plantations can provide the required light conditions that would promote growth of understory indigenous plants. The results implied that deforested areas in the highlands of Ethiopian can be restored by establishing plantation species through their influence on the light condition under their canopies. In this case Eucalyptus species such as E. saligna and E. globulus, with their open canopies, are particularly important as they can alter solar radiation which promotes regeneration of indigenous species as compared to the two major exotic plantation species, Pinuspatula and Cupressuslusitanica (Eshetu Yirdaw and Luuk Kanen, 2004; Mulugeta Lemenih et al., 2004). Following appropriate management interventions like thinning and avoiding weeding of regenerated woody plants, Eucalyptus plantations can even support the development of understory indigenous vegetation into secondary indigenous forest. At MunessaShashemene forest, for example, secondary Podocarpus forest had developed inside E. saligna plantation (Senbeta Feyera et al., 2002). Similarly secondary Juniperus forest had formed inside E. globulus plantations at Entoto (Personal observation). More information about ecophysiology of indigenous plants inside various plantation stands at several sites and various planting density based on many species is required to better understand the effect of plantation species and site conditions on the growth of indigenous seedlings, and to further promote the role of forest plantations as catalysts of succession (Parrotta et al., 1997) in the Ethiopian highlands.

\section{ACKNOWLEDGEMENT}

The authors are grateful to Awol Assefa for his support during data collection. We also thank the reviewers Dr. Adane Assefa and Dr. Ali Syed for their useful comments and suggestions which have helped to improve the quality of the paper. 


\section{REFERENCES}

Bekel Lemma, Dan, B.K., Ingvar, N \& Mats,O. 2006.Soil carbon sequestration under different exotic tree species in the southwestern highlands of Ethiopia.Geoderma,136: 886-898.

Bilger, W., Schreiber, U \& Bock, M. 1995.Determination of the quantum efficiency of photosystem II and non-photochemical quenching of chlorophyll fluorescence in the field.Oecologia, 102: 425-432.

Björkman, O. 1987. Low temperature chlorophyll fluorescence in leaves and its relationships to photon yield of photosynthesis in photoinhibition. In: Kyle, D.J., Osmond, C.B. \&Arntzen, C.J. (eds.),Photoinhibition.Elsevier Science Publishers, Amsterdam, pp.123144.

Demmig, B \& Björkman, O.1987. Comparison of the effect of excessive light on chlorophyll fluorescence $(77 \mathrm{~K})$ and photon yield of $\mathrm{O}_{2}$ evolution in leaves of higher plants. Planta,172: 378-385.

Desalegn Tadele. 2004. Growth and establishment of seedlings of indigenous plants inside plantations and adjacent natural forest. MSc thesis.Addis Ababa University, Addis Ababa, Ethiopia.57 p.

Desalegn Tadele \& Masresha Fetene. 2013. Growth and ecophysiology of seedlings of Podocarpusfalcatus in plantations of exotic species and in a natural montane forest in Ethiopia. Journal of Forestry Research, 24(1):29-35.

Eshetu Yirdaw \& Luukkanen, O. 2004. Photosynthetically active radiation transmittance of forest plantation canopies in the Ethiopian highlands. Forest Ecology and Management, 88: 17-24.

Feyera Senbeta \& Demel Teketay. 2001. Regeneration of indigenous woody species under the canopy of tree plantations in Central Ethiopia. Tropical Ecology, 42:175-185.

Feyera Senbeta, Demel Teketay \& Nslund, B.Å. 2002.Native woody species regeneration in exotic tree plantations at Munessa-Shashemene Forest, southern Ethiopia. New forests, 24: 131-145.

Fritzsche, F., Asferachew Abate, Masresha Fetene, Beck, E., Weise, S \& Guggenberger, G.2006.Soil-plant hydrology of indigenous and exotic trees in an Ethiopian montane forest. Tree Physiology, 26: 1043-1054. 
Gemedo Dalle \& Masresha Fetene. 2004. Gap-fillers in Munessa-Shashemene forest. Ethiopian Journal Biological Sciences, 3: 1-14.

Genty, B., Briantais, J.M \& Baker, N.R. 1989.The relationship between the quantum yield of photosynthetic electron transport rate and quenching of chlorophyll fluorescence. Biochimicaet Biophysica Acta, 990: 87-92.

Getachew Tesfaye \& Abiyot Berhanu.2006. Regeneration of indigenous woody species in the understory of exotic tree plantations in southwestern Ethiopia. Ethiopian Journal Biological Sciences, 5: 31-43.

Guerrero, P \& Bustamante, R. 2007. Can native tree species regenerate in Pinusradiata plantations in Chile? Evidence from field and laboratory experiments. Forest Ecology and Management, 253: 97-102.

Lugo, A.E. 1997. The apparent paradox of re-establishing species richness on degraded lands with tree monocultures. Forest Ecology and Management, 99: 9-19.

Lüttge, U., Masresha Fetene, Liebig, M., Rascher, U \& Beck, E. 2001.Ecophysiology of niche occupation by two giant rosette plants, Lobelia gibberoa Hemsl and Solaneciogigas (Vatke) C. Jeffrey, in an afromontane forest valley. Annals of Botany, 88: 267-278.

Mulugeta Lemenih \& Demel Teketay. 2005. Effect of prior land use on the recolonization of native woody species under plantation forests in the highlands of Ethiopia. Forest Ecology and Management, 218: 60-73.

Mulugeta Lemenih, Taye Gidyelew \& Demel Teketay. 2004. Effects of canopy cover and understory environment of tree plantations on richness, density and size of colonizing woody species in southern Ethiopia. Forest Ecology and Management, 194:1-10.

Ostertag, R., Giardina, C.P \& Cordell, S. 2008. Understory colonization of Eucalyptus plantation in Hawaii in relation to light and nutrient levels. Restoration Ecology, 16: 75-485.

Parrotta, J.A., Turnbull, J.W\& Jones, N.1997. Catalyzing native forest regeneration on degraded tropical lands. Forest Ecology and Management, 99: 1-7.

Schreiber, U., Bilger W \& Neubauer, C.1994. Chlorophyll fluorescence as a nonintrusive indicator for rapid assessment of in vivo photosynthesis. In: Schulze, E.D and Galdwell, M.M. (eds.), Ecophysiology of photosynthesis. Springer-verlag, Berlin, pp. 49-70.

Senbeta Feyera, Beck, E \& Lüttge, U. 2002. Exotic trees as nurse-trees for the regeneration of natural tropical forests. Trees, 16: 245-249. 
Shiferaw Alem \& Tadesse Woldemariam. 2009. A comparative assessment on regeneration status of indigenous woody plants in Eucalyptus grandis plantation and the adjacent natural forest. Journal of Forestry Research, 20:31-36.

Shiferaw Alem, Tadesse Woldemariam \& Pavlis, J. 2010. Evaluation of soil nutrients under Eucalyptus grandis plantation and adjacent sub-montane rainforest. Journal of Forestry Research, 21: 457-460.

Wang, J., Ren, H., Yang, L \& Daun, W. 2009. Establishment and early growth of introduced indigenous tree species in typical plantations and shrub land in South China. Forest Ecology and Management, 258: 1293-1300.

Yang, L., Liu, N., Ren, H. \& Wang, J. 2009. Facilitation by two exotic Acacia: Acacia auriculiformis and Acacia mangium as nurse plants in South China. Forest Ecology and Management, 257: 1786-1793. 